\title{
The Application of Big Data in Mapping and Geographic Information Technology
}

\author{
Dagui $\operatorname{Lin}^{1, a}$ and Bin $\mathrm{Li}^{2, \mathrm{~b},{ }^{*}}$ \\ ${ }^{1} 61287$ Troops, Lhasa, China; ${ }^{2}$ College of Information Science and Engineering, Henan University \\ of Technology, Zhengzhou, China

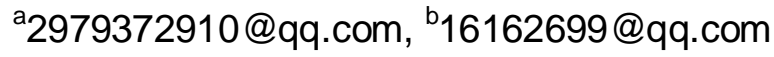 \\ ${ }^{*}$ The Corresponding author
}

Keywords: Surveying and Mapping Geographic Information; Big Data; Information Technology; Application

\begin{abstract}
With the development of computer network technology, big data is deep in the society. It has a strong era and application, and has produced application effects in various fields. Mapping and geographic information technology is also produced under the highly developed background of information technology. In order to meet people's demand for accurate geographic information and to better serve humanity, geographic information must be evaluated from all aspects. Big data can be Show their skills. How to deepen the value of data and adapt to the needs of the era of big data requires further breakthroughs and changes in the geographic data acquisition, processing, and application phases of mapping. This paper firstly summarizes the big data processing technology, points out the new contradictions and new issues faced by the mapping and geographic information services in the new era, and focuses on the application of big data in mapping geographic information, aiming to provide reference for relevant staff.
\end{abstract}

\section{Introduction}

In the era of big data, the practical application scope of the Internet of Things and cloud computing is constantly expanding, which has brought a greater impact on the traditional surveying and mapping of geographic information. Therefore, in order to better adapt to the development requirements of the era of big data, it is necessary to strengthen the deep thinking on the future development direction and work mode optimization of geographic information in the context of such times. The correct view of the characteristics of the era of big data from different perspectives has prompted the implementation of various surveying and mapping geographic information plans to achieve the desired results. It has also optimized the allocation of resources while expanding the scope of geographical information services for surveying and mapping. Under the influence of this situation, in order to maintain the high efficiency of surveying and mapping geographic information work and improve the quality of surveying and mapping geographic information, it is necessary to strengthen the deep understanding of big data, to promote the implementation of the relevant surveying and mapping work plans to achieve the desired results, and to strengthen the traditional surveying and mapping geography. The continuous improvement of the information work mode has broadened the working ideas in the work. At the same time, the development of surveying and mapping geographic information should strengthen the effective grasp of various opportunities in the era of big data, and prompt the related problems that existed to be handled in a timely manner to maximize the overall level of China's surveying and mapping industry. Based on this, this article will explore the application of big data and its application in surveying geographic information, as well as the enlightenment to the work.

\section{Common Big Data Processing Technology}

\section{HDFS file management system}

In the context of big data development, especially the use of Hadoop as the core of the 
non-structured document distributed storage file system, it can implement an effective solution for file management. It basically has the following characteristics. Firstly, it can be deployed on relatively low cost hardware with low application cost. The cost of expansion in the system is relatively low, and it is relatively simple and convenient when it is implemented. The second is data that can support high-throughput and high-concurrent access to applications, and can be used in very large data clusters, and can access large concurrent file management. The third is a strong expansion. Use Map Peduce to implement distributed computing, clustering configuration data, and computing tasks. These clusters can be easily extended to thousands of nodes. Therefore, HDFS can solve the problem that files cannot be stored centrally in file management. In addition, it also supports related formats such as documents, audio and video, and includes HDV and Impala-related structured databases on the basis of the HDFS database, which can perform queries and update work.

\section{Cloud storage}

The so-called cloud storage is a new concept extended in cloud computing. It is a new type of network storage technology. After cluster applications, network technologies, or related functions such as HDFS, various kinds of storage devices in the network are collected through application software. Coordinate work together, together with data storage and business access systems. In a word, cloud storage is a new technology that puts storage resources on the cloud to provide people with storage and extraction.

\section{Knowledge map}

As a map of knowledge, it is a structure built on the basis of graph data. It is essentially a semantic network composed of nodes and edges. In the knowledge map, nodes can represent entities in the real world, and each edge is the relationship between entities and entities. Knowledge map is a way to present the relationship concretely. It connects all different types of information together to obtain a network of relationships. Knowledge maps can analyze problems in relational positions. When knowledge maps are widely used, many companies apply them to document management to effectively manage document relationships and obtain document knowledge points, providing support for later document management.

\section{Gradual Mapping of Geographical Big Data}

With the rapid development of modern surveying and mapping science and technology, the acquisition and processing capabilities of geographical data for surveying and mapping have been greatly improved. From satellites, aviation, and low-altitude UAVs to ground-based surveying robots and underground geophysical surveying radars, the integrated information acquisition and processing capabilities of heaven and earth have been formed. In China, especially in the past 20 years, the country, provinces, and cities have promoted a series of major surveying and mapping geographic projects, and accumulated massive surveying and mapping geographic data, including multi-source remote sensing image data, basic geographic spatial data, urban underground pipeline data, and urban underground space data. , the city's three-dimensional fine model, and so on, formed an underground, indoor and outdoor integration mapping geographic data. In addition, major projects such as forestry surveys, water resources surveys, land resource surveys, geographical names surveys, and geographic national surveys have also been carried out in the country at the same time. This has also greatly enriched the geographical data content of surveying and mapping and expanded the geographic data extension.

At present, we have acquired abundant data resources such as natural geography, human geography, and economic geography. These data include both structured geographic information big data types, such as remote sensing image data, navigation and positioning data, geodetic reference data, map data, and attributes of various types of features associated with locations. It also includes unstructured geographic information big data types, such as social and business fragmented text description data associated with locations, location-related images, video, voice, and other data and movement trajectory data. The all-round, multi-temporal and geographical data provide a possibility for human beings to more thoroughly perceive and plan, manage and manage our living 
environment more wisely.

\section{The Opportunity Brought by the Era of Big Data for Mapping Geographic Information Work}

\section{Opportunities in Mapping Geographic Information Services}

In the process of carrying out relevant work plans of the surveying and mapping geographic information department, it is possible to obtain a wealth of geographical data for surveying and mapping in accordance with the actual requirements of actual production activities to ensure the smooth completion of the construction of surveying and mapping projects. In the era of big data, the application scope of information technology and computer network technology is more extensive, and has produced good effects in the specific application process. This has created favorable conditions for the construction of mapping geographic information databases and the continuous improvement of service functions. At the same time, due to the impact of big data, China's digital mapping geospatial framework is continuously being completed, and the scale of island construction is gradually expanding, creating favorable conditions for the continuous improvement of the work level of the modern surveying and mapping geographic information department. Combining the actual development of the surveying and mapping of geographic information departments at the present stage, we can see that the arrival of the era of big data has brought about a major increase in the adaptability of geographic information technology to 3D space mapping, and the reliability of the technology has been significantly improved. The acquisition of marine basic geographic information data provides important technical support.

\section{Opportunities in Building Smart Cities}

Through the development and application of digital maps and the integrated use of different data types, professional organizations for surveying and mapping geographic information can effectively carry out plans for the construction of smart cities, and promote the development of digital cities to a more advanced stage, gradually forming a variety of new models in line with the development of modern cities. Compared with the traditional urban development model, the greatest feature of a smart city is that it can make all people's lifestyles and business models of all industries highly intelligent, and meet the actual needs of modern urban construction to the maximum extent possible. To achieve such development goals, it is necessary to grasp the era of big data to bring good development opportunities for geographical information mapping: Through the continuous integration of various data resources, with the support of sensors and automatic control technology, improve the efficiency of the use of geographical data. Establish a new model that meets the requirements for the development of smart cities and realize the deep mining and application of big data.

\section{Opportunities in Building Mapping Geographic Information Systems}

At this stage, relevant departments of surveying and mapping geographic information need to improve the utilization efficiency of massive data under the influence of the era of big data, and still face greater challenges in building a reliable geographic information system. However, due to the abundance of various resources in the era of big data and the continuous improvement of related technologies, it will help bring about new development concepts and development models for the stable development of geographic information departments and geographic information companies for mapping. It has created favorable conditions for the construction of a professional mapping geographic information system. Therefore, in order to increase the efficiency of surveying geographic information utilization and expand the practical application scope of surveying and mapping geographic information, it is necessary to combine the development situation in the era of big data, build a reliable surveying and mapping geographic information system, continuously improve the system's service functions, and promote the operation of surveying and mapping geographic information system, providing reliable protection for the improvement of the utilization efficiency of geographic information resources. Improve the chances of integration of cloud computing, cloud services, and other innovative models to meet various needs in the implementation of mapping and geographic information operations plans, enhance the efficiency of various surveying and mapping geographic information data mining in system operations, and 
accelerate the overall development of modern surveying and mapping geographic information industry speed. The different contents of these aspects objectively illustrate the importance of deep understanding of the relevant content of the era of big data for the construction of mapping geographic information systems.

\section{Measures to Further Promote the Upgrade and Transformation of Surveying and Mapping Geographic Information Services}

\section{Adhere to the concept of developing large surveying and mapping}

To a certain extent, the advent of the age of big data signals that China has fully entered the era of large-scale surveying and mapping. In the previous few years, the party group of the National Surveying and Mapping Geographical Information Bureau put forward the concept of "large surveying and mapping, great science and technology, big industry, and great development". In order to better practice this concept of development, relevant personnel must always adhere to the concept of development of large surveying and mapping in the era of big data, actively integrate surveying and mapping of geographic information interests with the overall interests of economic and social development, and vigorously improve the lack of geographic information services for surveying and mapping, strengthen its administrative level, maximize the development of the value of geographic information applications, and fundamentally promote the development of China's surveying and mapping geography.

\section{Fully respect the development laws of the market economy}

Surveying and mapping geographical information administrative management needs to meet the development requirements of the era of big data, must follow the law of the development of the market economy, according to the specific requirements of market economic laws to promote the development of surveying and mapping geographic information services. In order to better accelerate the innovation of government functions and management, the relevant government should strengthen the supervision of the service industry and the market, and try to make public services become the main direction of future economic development. On this basis, we will integrate geographic information services with life services, create products that meet the requirements of the service, and actively provide users with personalized geographic information services.

\section{Properly reform geographic information management system for surveying and mapping}

The advent of the era of big data has had a certain impact on the production relations and distribution relations of traditional industries, and has greatly enhanced the operating efficiency and structural efficiency of related systems, making it possible for industries to achieve transformation and upgrading. Therefore, the geographical information service of surveying and mapping at this stage should firmly grasp the advantages of development in the era of big data, strengthen the implementation of the geographical distribution of production and distribution of geographical information, process flow and information security, and make it adapt to the development trend of the times. In addition, mapping geographic information services should vigorously develop geographic design services, provide users with better services, and promote the development of geographic information management services.

\section{Summary}

With the advent of the era of big data, data information has become the focus of competition in various industries, which has brought about a good development opportunity for the optimization and upgrading of mapping and geographic information service systems. However, it should be noted that the characteristics of development in the era of big data have caused a serious impact on the original service processing model. When workers actually deal with relevant service information, they will still have certain limitations. Faced with this situation, the relevant staff should be bold in reform and innovation, combine the development advantages of big data, make up for deficiencies in traditional mapping and geographic information services, take the initiative to 
upgrade and transform, seize the development opportunities of the times, and obtain better Development results.

\section{References}

[1] Huang X Y. Research on Application of Surveying and Mapping Geographic Information Technology in the Rural Land Survey[J]. Geomatics \& Spatial Information Technology, 2013.

[2] Zhang H T. The Integrated Surveying and Mapping Technology in Urban Fundamental Geographic Information Data Update and Application[J]. Beijing Surveying \& Mapping, 2012.

[3] Mei S H, Qi H E. Construction and Realization Archival Resources of Surveying,Mapping and Geographic Information in the Big Data Era[J]. Geomatics \& Spatial Information Technology, 2016.

[4] Arvor D, Durieux L, Andrés S, et al. Advances in Geographic Object-Based Image Analysis with ontologies: A review of main contributions and limitations from a remote sensing perspective[J]. Isprs Journal of Photogrammetry \& Remote Sensing, 2013, 82(8):125-137.

[5] Zhao J. Application of organization codes in Big Data era[J]. Science of Surveying \& Mapping, 2014.

[6] Han dong H U. Opportunities and Challenges of Surveying Geographic Information Industry in the Big Data Era[J]. Geomatics \& Spatial Information Technology, 2015.

[7] Shi H W, Jian Y T. The role of Surveying and Mapping geographic information in Mining area construction research[J]. World Nonferrous Metals, 2017.

[8] Chen Z D. Discussion on the geographic information service of mine surveying and mapping under the condition of big data development[J]. World Nonferrous Metals, 2017.

[9] Wang J N. Surveying and Mapping Geographic Information Application in the Emergency of Surveying and Mapping Analysis[J]. Intelligent Building \& Smart City, 2017.

[10] Liu, Zong Bo. "Analysis of geographic information service of mine surveying and mapping under the development of big data." World Nonferrous Metals (2017).

[11] De-Lin L I, Jia C D. Basic Geographic Information Data Update Occurs the Application of Cadastral Surveying and Mapping Results[J]. Geomatics \& Spatial Information Technology, 2016.

[12] Ren H, Ren Y. How to Apply Geographic Information in Surveying and Mapping Works[J]. Beijing Surveying \& Mapping, 2017.

[13] Liu Z B. Analysis of geographic information service of mine surveying and mapping under the development of big data[J]. World Nonferrous Metals, 2017.

[14] Zhang Q. On the Construction of Surveying and Mapping Geographic Information System[J]. Value Engineering, 2018. 